\title{
QUIZ: Qual dos diagnósticos abaixo, baseado no ECG, é o mais provável?
}

DOI: $10.5380 /$ rmu.v1i2.40870

Caso Clínico: Um homem de 23 anos, portador de glioblastoma recidivante de fossa posterior, em tratamento por radioterapia (última sessão há dois meses), é internado por sepse pulmonar grave. Desenvolveu choque séptico, insuficiência renal aguda e insuficiência respiratória, com necessidade de intubação orotraqueal. Após o tratamento instituído, evoluiu bem. Porém, no quarto dia de tratamento, apresentou taquicardia e mudança do padrão eletrocardiográfico, sem instabilidade hemodinâmica. Realizou TAC de crânio, porém não foram evidenciadas novas alterações, exceto o acometimento da fossa posterior e do tronco encefálico.

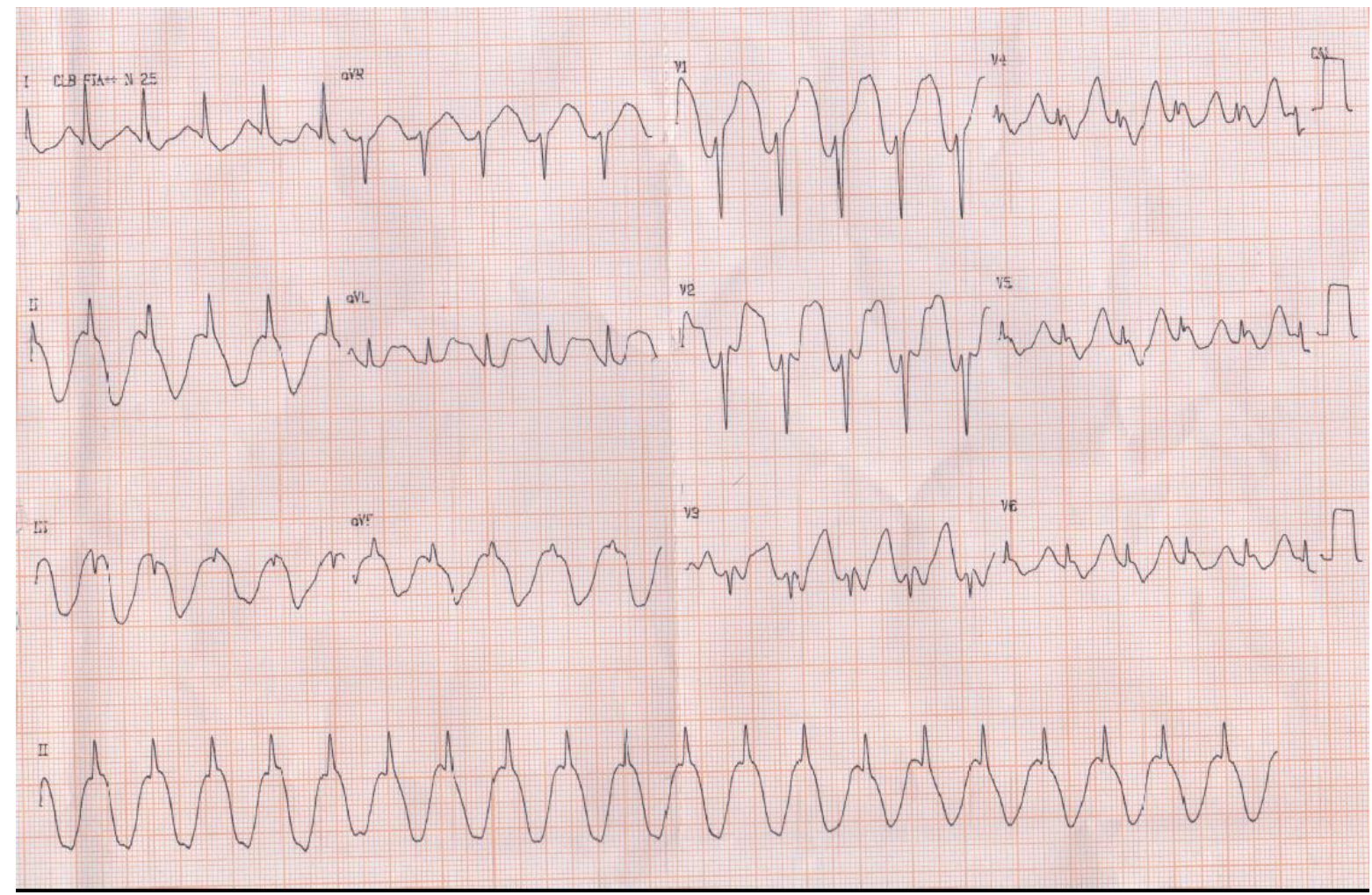

A. Síndrome coronariana aguda com isquemia subepicárdica.

B. Traçado e quadro clínico sugestivo de vagotonia.

C. Hipocalcemia ou hipercalemia.

D. Onda T cerebral 


\title{
REVISTA MÉDICA DO HC-UFPR
}

\section{E. Torção das pontas (Torsades de pointes).}

\section{RESPOSTA D}

Este paciente é jovem, com ausência de fatores de risco clássicos para doença arterial coronariana e apresentou alterações em todas as derivações eletrocardiográficas, não delimitando um território correspondente a alguma artéria coronária. Além disso, as ondas T isquêmicas quando presentes são simétricas.

O paciente encontrava-se com quadro séptico, com aumento das catecolaminas circulantes e não teve nenhuma manifestação de vagotonia, que se apresenta como onda $\mathrm{T}$ apiculada e positiva. Exames laboratoriais não demonstraram nenhuma alteração metabólica, com níveis normais de cálcio, potássio e magnésio. O traçado eletrocardiográfico na torsades de pointes evidencia taquicardia ventricular polimórfica, com impressão de rotação em torno da linha de base. Está associada a prolongamento do intervalo QT.

Este caso ilustra a manifestação eletrocardiográfica de onda T cerebral. São ondas gigantes, negativas, presentes em todas as derivações eletrocardiográficas. São acompanhadas de desnivelamento do segmento ST e aumento do intervalo QT. São mais comuns em hemorragia cerebral e atribuídas à intensa disfunção autonômica causada pela lesão aguda.

\section{REFERÊNCIAS BIBLIOGRÁFICAS}

1. Friedmann, A. A; Grindler, J.; Oliveira, C.A.R.; Diagnóstico diferencial no Eletrocardiograma. São Paulo: Manole, 2007. 204p.

\author{
1-Universidade Federal do Paraná

